Funding: None; Competing interest: None stated.

\section{REFERENCES}

1. di Sant'Agnese PA, Darling RC, Perera GA, Shea E. Sweat electrolyte disturbances associated with childhood pancreatic disease. Am J Med. 1953;15:777-84.

2. Accurso FJ, Rowe SM, Clancy JP, Boyle MP, Dunitz JM,
Durie PR, et al. Effect of VX-770 in persons with cystic fibrosis and the G551D-CFTR mutation. N Engl J Med. 2010;363:1991-2003.

3. Kawoosa MS, Bhat MA, Ali W, Hafeez I, Shastri S. Clinical and mutation profile of children with cystic fibrosis in Jammu and Kashmir. Indian Pediatr. 2014;51:185-9.

\title{
CFTR Mutations in India: Need to do More! GENETICIST'S PERSPECTIVE
}

\author{
KATTA M GIRISHA \\ Division of Medical Genetics, Department of Pediatrics \\ Kasturba Medical College, Manipal University, Manipal-576 104 \\ girish.katta@manipal.edu
}

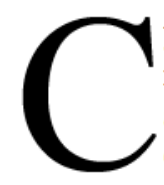
ystic fibrosis is an autosomal recessive multisystem disease with significant morbidity and mortality in all parts of the world. Contrary to the popular belief, early genetic studies on cystic fibrosis confirmed that the condition does occur in India and the most prevalent delta F508 mutation occurred frequently, in $19-56 \%$ of cases [1-3]. The largest series on mutation analysis in Indian patients found that delta F508 mutation accounted for 31.1\% mutations [4]. It was also noted that Indians may have a different spectrum of mutations as several new mutations were observed [4-6]. The carrier frequency of $0.42 \%$ appears to be an underestimate considering a 10 times higher incidence in Caucasians and the disease is not studied well in Indian population [7]. It also needs to be emphasized that it is not easy to diagnose and manage this condition in our country [8].

Kawoosa and colleagues [9] have screened a group of patients with clinical symptoms of cystic fibrosis from Jammu and Kashmir. Then they performed testing for two specific mutations known to cause cystic fibrosis in selected group of 15 patients with the diagnosis of cystic fibrosis. It is important to note that the authors have chosen to screen only for two mutations. Though this is often used as a strategy in a resource-scarce setting, given the allelic heterogeneity, it would have been better to screen the entire gene. Labeling cases with only one mutation as cystic fibrosis transmembrane conductance regulator related metabolic syndrome is also not appropriate as the entire gene was not sequenced in them. They could identify only 16 alleles in 15 patients leaving nearly half the alleles unidentified. Hence it would be premature to draw conclusions on the commonality of the mutations considering the small study group and mutation detection strategy. Nevertheless this study highlights the frequency of the condition and two selected mutations in the studied population and the need for effective strategies for mutation detection that can go a long way to offer genetic counseling services for these families.

Recently mutation-specific treatment has been tried in patients with at least one G551D mutation that was based on prior knowledge of the effect of the mutation on CFTR channel and its repair by the drug $[10,11]$. Hence it is important that such studies are expanded to provide comprehensive mutation testing facilities for this condition in our country as we get ready to offer newborn screening for this condition.

Funding: None. Competing interests: None stated.

\section{REFERENCES}

1. Kabra SK, Kabra M, Lodha R, Shastri S, Ghosh M, Pandey RM, et al. Clinical profile and frequency of delta f508 mutation in Indian children with cystic fibrosis. Indian Pediatr. 2003;40:612-9.

2. Ashavaid TF, Raghavan R, Dhairyawan P, Bhawalkar S. Cystic fibrosis in India: a systematic review. J Assoc Physicians India. 2012;60:39-41.

3. Kabra M, Ghosh M, Kabra SK, Khanna A, Verma IC. Delta F 508 molecular mutation in Indian children with cystic fibrosis. Indian J Med Res. 1996;104:355-8.

4. Sachdeva K, Saxena R, Puri R, Bijarnia S, Kohli S, Verma IC. Mutation analysis of the CFTR gene in 225 children: identification of five novel severe and seven reported severe mutations. Genet Test Mol Biomarkers. 2012;16:798-801.

5. Sharma N, Singh M, Kaur G, Thapa BR, Prasad R. 
Identification and characterization of CFTR gene mutations in Indian $\mathrm{CF}$ patients. Ann Hum Genet. 2009;73:26-33.

6. Kabra M, Kabra SK, Ghosh M, Khanna A, Arora S, Menon PS, et al. Is the spectrum of mutations in Indian patients with cystic fibrosis different? Am J Med Genet. 2000;93:161-3.

7. Kapoor V, Shastri SS, Kabra M, Kabra SK, Ramachandran V, Arora S, et al. Carrier frequency of F508del mutation of cystic fibrosis in Indian population. $\mathrm{J}$ Cyst Fibros. 2006;5:43-6.

8. Kabra SK, Kabra M, Shastri S, Lodha R. Diagnosing and managing cystic fibrosis in the developing world. Paediatr Respir Rev. 2006;7:S147-50.
9. Kawoosa MS, Bhat MA, Ali W, Hafeez I, Shastri S. Clinical and mutation profile of children with cystic fibrosis in Jammu and Kashmir. Indian Pediatr. 2014;51:185-9.

10. Eckford PD, Li C, Ramjeesingh M, Bear CE. Cystic fibrosis transmembrane conductance regulator (CFTR) potentiator VX-770 (ivacaftor) opens the defective channel gate of mutant CFTR in a phosphorylationdependent but ATP-independent manner. J Biol Chem. 2012;287:36639-49.

11. Ramsey BW, Davies J, McElvaney NG, Tullis E, Bell SC, Drevinek $\mathrm{P}$, et al. A CFTR potentiator in patients with cystic fibrosis and the G551D mutation. N Engl J Med. 2011;365:1663-72. 